record of any real value. And some people would be rather shy of acknowledging that any of their ancestors had been addicted to an immoderate consumption of alcohol. But this is a digression.

The chapter on the social achievements and frustrations should be of real value to the public.

The book is well produced, paper, print and illustrations are all good and we only noticed a single misprint. As this struck us as rather an amusing one we hope that the author will pardon our noticing it. On page 145, what we think should have been "acholuric" jaundice appears as "alcoholic" jaundice. If we are wrong and the jaundice really is alcoholic we will beg pardon, but we note that it is given its more sober title in the index.

\title{
CORRESPONDENCE
}

\section{OPHTHALMOLOGICAL “NOTES AND QUERIES."}

To the Editors of THE BRITISH JOURnaL OF OPHTHALMOLOGY.

DEAR SIRS.-The usefulness of your Journal could be greatly extended, in my opinion, by reserving a portion for "Queries and Answers" similar to that in the British Medical Journal. It would afford an opportunity for "the strong to help the weak" and make interesting reading for all of us.

In addition to this the recording of interesting cases in our everyday work should be encouraged. Such records, though brief, would be very valuable for future reference.

These two additions to your Journal would help to meet the justifiable plea made for more clinical articles by one of your readers a few months ago.

WOODTHORPE,

Yours faithfully,

Francis E. Preston.

St. Mary's Avenue,

WANSTEAD.

November 19, 1941.

\section{THE CAUSATION OF "RETROBULBAR NEURITIS"}

To the Editors of The British Journal of Ophthalmology.

DEAR SIRS.-In a paper on Retrobulbar Neuritis and Peripheral Neuritis in the December number of the Journal the following 